\title{
Flame Synthesis of Complex Fluoride-Based Nanoparticles as Upconversion Phosphors ${ }^{\dagger}$
}

\author{
Alexander Stepuk ${ }^{1}$, Karl W. Krämer ${ }^{2}$ and Wendelin J. Stark ${ }^{1 *}$ \\ ${ }^{1}$ Department of Chemistry and Applied Biosciences Institute for Chemical and Bioengineering \\ ${ }^{2}$ Department of Chemistry and Biochemistry, University of Bern
}

\begin{abstract}
Recent improvements in precursor chemistry, reactor geometry and run conditions extend the manufacturing capability of traditional flame aerosol synthesis of oxide nanoparticles to metals, alloys and inorganic complex salts. As an example of a demanding composition, we demonstrate here the one-step flame synthesis of nanoparticles of a 4-element non-oxide phosphor for upconversion applications. The phosphors are characterized in terms of emission capability, phase purity and thermal phase evolution. The preparation of flame-made $\beta-\mathrm{NaYF}_{4}$ with dopants of $\mathrm{Yb}, \mathrm{Tm}$ or $\mathrm{Yb}, \mathrm{Er}$ furthermore illustrates the now available nanoparticle synthesis tool boxes based on modified flamespray synthesis from our laboratories at ETH Zurich. Since scaling concepts for flame synthesis, including large-scale filtration and powder handling, have become available commercially, the development of industrial applications of complex nanoparticles of metals, alloys or most other thermally stable, inorganic compounds can now be considered a feasible alternative to traditional top-down manufacturing or liquid-intense wet chemistry.
\end{abstract}

Keywords: flame pyrolysis, upconversion, sodium yttrium fluoride, rare earth, luminescence, nanoparticles

\section{Introduction}

Nanoparticle powder technology is a widely applied industrial process for the preparation of advanced functional materials (Hosokawa, 2008). Predesigned and engineered nanostructures attract the interest of research and industry communities. Various methods of synthesis and control of these objects are constantly being developed and appear in high-impact journals, symposia and discussions. Despite a dramatic gap between academic methods for laboratory synthesis and the technological implementation on an industrial scale, various materials based on nanotechnologies are already available from large-scale production. Among the most promising methods are: CVD process for carbon nanotubes (Cassell et al., 1999); emulsion methods for polymer-

\footnotetext{
Accepted: September 10, 2012

ETH Zurich 8093 Zurich, Switzerland

3012 Bern, Switzerland

* Corresponding author:

E-mail: wendelin.stark@chem.ethz.ch

TEL: +41-44-632-0980 FAX: +41-44-633-1571
}

ic nanoparticles (Muller et al., 2006) in drug delivery applications (PLGA, (Musyanovych et al., 2008)); solgel, e.g. $\mathrm{LiFePO}_{4}$ (Lee et al., 2010); precipitation, e.g. $\mathrm{BaSO}_{4}$, (Adityawarman et al., 2005); and hydrothermal methods (Chen et al., 2009) for various nanoparticles. However, the aforementioned methods are often inapplicable for metastable phases which often possess high functional characteristics.

Gas-phase synthesis stands aside as an independent process to fabricate nanopowders, particularly with aerosol methods. This technique allows a multiscale and cheap production of nanoparticles. It is a relatively flexible technology by which also metastable phases can be obtained. Flame pyrolysis is currently applied in the large-scale production of $\mathrm{SiO}_{2}$ and $\mathrm{TiO}_{2}$ nanoparticles. The method is also promising for the production of nanostructured carbonates, e.g. $\mathrm{CaCO}_{3}$ (Huber et al., 2005) and $\mathrm{SrCO}_{3}$ (Strobel et al., 2006), sulfides, e.g. $\mathrm{PbS}$ and $\mathrm{ZnS}$ (Athanassiou et al., 2010), highly reactive metals, e.g. Co (Grass and Stark, 2006) and $\mathrm{Ni}$ (Jung et al., 2005), alloys, e.g. Cu$\mathrm{Ni}$ (Jung et al., 2003), glasses, e.g. $\mathrm{SiO}_{2}-\mathrm{CaO}-\mathrm{P}_{2} \mathrm{O}_{5}-$ $\mathrm{Na}_{2} \mathrm{O}$ (Brunner et al., 2006), and halides, e.g. $\mathrm{NaCl}$, 
$\mathrm{BaF}_{2}$, and $\mathrm{CaF}_{2}$, (Grass and Stark, 2005). An overview oflnapoparticles prepared by flame-spray pyrolysis is shown in Fig. 1. The established materials, namely spherical oxide nanoparticles, a straightforward product of gas-phase synthesis, stand at the origin of the graph. This group typically includes titanium, silicon, and aluminum oxides. There has been evidence for more complex materials prepared by flame pyrolysis, e.g. $\mathrm{Sr}_{5}\left(\mathrm{PO}_{4}\right)_{3} \mathrm{Cl}: \mathrm{Eu}^{2+}$ (Kang et al., 2003). A reducing atmosphere helps to step away from oxidic nanoparticles towards metallic compounds. Acetylene-fed flames form carbon shells on the surface of metallic nanoparticles (Grass et al., 2007). Such carbon coatings allow chemical functionalization strategies of the nanoparticle surface to use them in filtration and purification (Rossier et al., 2011), magnetic chemical reagents (Wittmann et al., 2010) and catalysts (Zeltner et al., 2011). Sulfides derived from flame pyrolysis belong to another group of widely applied chalcogenide salts. Recently, Athanassiou et al. successfully prepared doped $\mathrm{ZnS}: \mathrm{Mn}^{2+}$ nanoparticles (Athanassiou et al., 2010).

Another group of industrially valuable non-oxidic salts are halides. Chlorides and fluorides of alkaline and alkaline-earth metals have been successfully obtained by gas-phase synthesis yielding nanoparticles of various morphologies and structures. Fluorides have unique optical and electronic properties which are widely used in biomaterials and electronic applications, though the need of more complex phosphors requires the preparation of glasses and mixed fluorides.

Recently, upconversion (UC) phosphors based on the rare earth and alkaline-earth materials have been investigated. In a UC process several low energy photons are absorbed, their energy is converted and finally a photon of higher energy is emitted. UC is also known as anti-Stokes emission (Auzel, 2004). It is known for f-elements such as the lanthanide ions $\mathrm{Er}^{3+}$ and $\mathrm{Tm}^{3+}$, as well as $\mathrm{U}^{3+}$, and several d-element ions embedded into specific matrices (Auzel, 2004).

Upconversion phosphors such as $\beta-\mathrm{NaYF}_{4}: \mathrm{Yb}$, Tm or Yb, Er are regularly synthesized as bulk microcrystalline materials by high-temperature solidstate synthesis:

$$
\begin{aligned}
& \mathrm{NaF}+(1-\mathrm{x}-\mathrm{y}) \mathrm{YF}_{3}+\mathrm{xErF}_{3}+\mathrm{yYbF}_{3} \\
& \quad \rightarrow \mathrm{NaYF}_{4}:\left(\mathrm{xEr}^{3+}, \mathrm{yYb}^{3+}\right)
\end{aligned}
$$

Targeting molecules in biological applications and thin coatings for solar cells imply size limits of the embedded upconversion particles from tens to hundreds of nanometers. For the same purposes, it is preferable to produce upconversion nanoparticles with high luminescence intensity. Few approaches in the production of nanocrystalline UC phosphor materials are known: decomposition of multiprecursors (Yi et al., 2004), co-precipitation (Martin et al., 1999), hydrothermal and solvothermal methods (Zeng et al., 2005). Nonetheless, those methods are limited to predictable crystallite morphology, low production rates and complicated synthesis schemes. Hexagonal sodium yttrium fluoride is one of the most efficient host matrices for NIR-to-visible upconversion phosphors (Sommerdijk, 1973). The upconversion efficiency of sodium yttrium fluoride host matrices is 20 times higher compared to $\mathrm{La}_{2} \mathrm{O}_{3}$ and 6 times - to $\mathrm{La}_{2}\left(\mathrm{MoO}_{4}\right)_{3}$ crystal matrices (Blasse and Grabmaier, 1994). $\mathrm{NaYF}_{4}$ : Yb,Er or Yb,Tm upconversion phos-
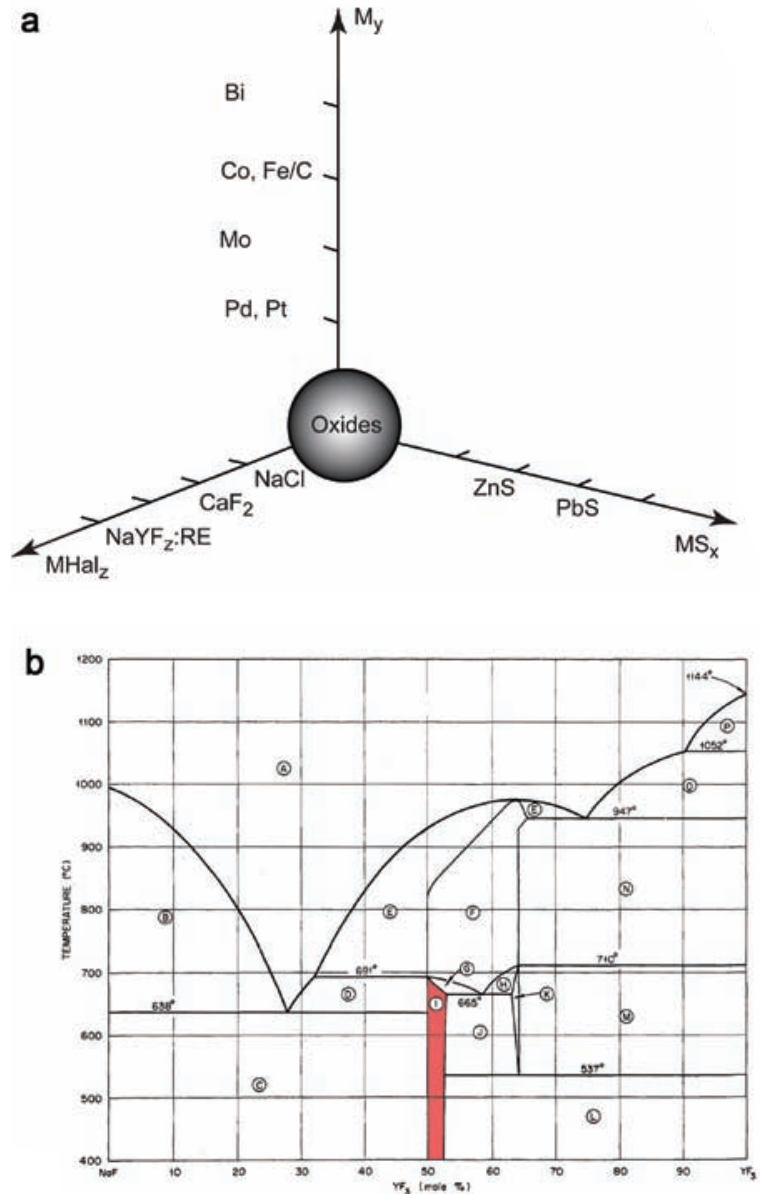

Fig. 1 (a) Schematic representation of various nanostructures currently available by the flamepyrolysis technique and (b) phase diagram of the $\mathrm{NaF}_{-} \mathrm{YF}_{3}$ system (Thoma et al., 1963). The shaded area marks the hexagonal $\mathrm{NaYF}_{4}$ stability region. Adapted with permission from Thoma et al., 1963. Copyright 1963 American Chemical Society. 

et al., 2004). The prospective applications of such phosphors include bio labels (Wang et al., 2009), solar cells (Richard and Shalav, 2005) and solid-state lasers (Sandrock et al., 1997).

Lim et al. (Lim et al., 2009) successfully produced sub-10-nm polydisperse UC nanophosphors by flamespray pyrolysis in a one-step continuous synthesis. The host matrix used for their study was cubic $\mathrm{Y}_{2} \mathrm{O}_{3}$ which is less efficient than hexagonal $\mathrm{NaYF}_{4}$ (Auzel, 2004). Grass et al. (Grass and Stark, 2005) proposed a fluoride doping with rare earth elements by flame synthesis. As a result, it appeared feasible to synthesize upconverting sodium yttrium fluoride nanoparticles doped with $\mathrm{Yb}$-Tm or Yb-Er, although the cubic phase might be obtained instead of the hexagonal phase which shows better UC properties. Due to the limited thermodynamic stability of the hexagonal low-temperature phase, see the phase diagram in Fig. 1b, the cubic high-temperature phase of $\mathrm{NaYF}_{4}$ might be obtained from the synthesis as metastable kinetic product.

In the present work, flame pyrolysis is used to prepare nanoparticles of non-oxidic, doped rare earth fluorides. The upconversion emission during excitation with NIR laser and the thermal behavior of the derived phosphors are analyzed. The cubic-to-hexagonal phase transition of $\mathrm{NaYF}_{4}$ will be examined for various syntheses and thermal treatment conditions.

\section{Experimental}

\section{Preparation of $\mathrm{NaYF}_{4}: \mathrm{Yb}(\mathrm{Tm}, \mathrm{Er})$ nanoparti- cles}

Powders of nano-sized upconversion particles (UCNP, $\mathrm{NaYF}_{4}$ : $\mathrm{Yb}, \mathrm{Tm}$ ) were fabricated by flamespray pyrolysis. Precursors of yttrium, ytterbium, erbium, and thulium were prepared from rare earth acetates $\mathrm{Tm}\left(\mathrm{CH}_{3} \mathrm{CO}_{2}\right)_{3} \cdot \mathrm{xH}_{2} \mathrm{O}, \mathrm{Y}\left(\mathrm{CH}_{3} \mathrm{CO}_{2}\right)_{3} \cdot \mathrm{xH}_{2} \mathrm{O}$ (Fluka, $99.90 \%$ metal trace), and $\mathrm{Yb}\left(\mathrm{CH}_{3} \mathrm{CO}_{2}\right)_{3} \cdot \mathrm{xH}_{2} \mathrm{O}$ (Acros Organics, $99.90 \%$ metal trace) by refluxing them with 2-ethylhexanoic acid (Fluka, puriss.) (Stark et

Table 1 Precursor synthesis conditions

\begin{tabular}{|l|l|l|l|}
\hline Salt ion & $\begin{array}{l}\text { Temperature, } \\
{ }^{\circ} \mathrm{C}\end{array}$ & $\begin{array}{l}\text { Distillation time, } \\
\text { hours }\end{array}$ & $\begin{array}{l}\text { Concentration, } \\
\text { wt. \% }\end{array}$ \\
\hline $\mathrm{Y}^{3+}$ & 130 & 6 & 6.3 \\
\hline $\mathrm{Yb}^{3+}$ & 110 & 12 & 8.32 \\
\hline $\mathrm{Tm}^{3+}$ & 120 & 2 & 0.7 \\
\hline
\end{tabular}

al., 2003, 2004, 2005) and removal of acetic acid, for experimental conditions see Table $\mathbf{1}$. In the case of erbium-doped phosphors, $\mathrm{Er}\left(\mathrm{CH}_{3} \mathrm{CO}_{2}\right)_{3} \cdot \mathrm{xH}_{2} \mathrm{O}$ (Fluka, $99.90 \%$ metal trace) was dissolved in 2-ethylhexanoic acid and the solution was directly combusted in the flame. $\mathrm{NaHCO}_{3}$ (Ph Eur, Applichem Co.) was mixed with 2-ethylhexanoic acid to obtain the sodium precursor. Each precursor solution was diluted with $\mathrm{xy}-$ lene (technical grade) to adjust the metal content to $1 \mathrm{M}$ and was filtered before combustion.

The prepared stoichiometric mixtures of rare earth ethylhexanoates, sodium 2-ethylhexanoate, and fluorobenzene (ABCR-Chemicals, 99\%) were combusted to produce $\mathrm{NaYF}_{4}$ nanoparticles, doped with 25 mol.\% $\mathrm{Yb}$ and $0.3 \mathrm{~mol} \% \mathrm{Tm}$, i.e. $\mathrm{NaY}_{0.747} \mathrm{Yb}_{0.25} \mathrm{Tm}_{0.003} \mathrm{~F}_{4}$, and 20 mol.\% $\mathrm{Yb}$ and 2 mol.\% Er, i.e. $\mathrm{NaY}_{0.78} \mathrm{Yb}_{0.2} \mathrm{Er}_{0.22} \mathrm{~F}_{4}$. The solution was pumped through a 0.4 -mm-diameter capillary at rates of $3,5,7$, and $91 \mathrm{~min}^{-1}$ into fuel flames. Alternatively, the liquid solution was dispersed into an aerosol and burnt in oxygen (99.8\%, Pan Gas) at rates of 7, 5, and $31 \mathrm{~min}^{-1}$ with a pressure drop at the capillary tip of 1.5 bar. A steady combustion was achieved by an oxygen (99.8\%, Pan Gas) sheath gas flow of $230 \mathrm{l} \mathrm{h}^{-1}$ through a concentric sinter metal ring. A Teflon filter was used to collect the prepared particles of UCNP. The particles remained stable at ambient conditions. In the case of the reducing flame pyrolysis, the precursors were burned in a nitrogen-rich atmosphere using a nitrogen $(5 \mathrm{~N}$, PanGas) glove-box with gas flow (Grass et al., 2007). This flow was circulated by a vacuum pump (Busch, Seco SV1040CV). The oxygen concentration was fixed below $100 \mathrm{ppm}$ (volumetric) for the reducing flame pyrolysis.

\section{Characterization of UC phosphors}

The specific surface area was calculated by measuring the nitrogen adsorption at $77 \mathrm{~K}$ on a Tristar (Micromeritics Instruments) following the Brunauer-Emmett-Teller (BET) method. Prior to the surface area determination, samples were preheated in vacuum at $150^{\circ} \mathrm{C}$ with $\mathrm{p}<0.1$ mbar during 1 hour.

The prepared $\mathrm{NaYF}_{4}$ nanoparticles with $\mathrm{Yb}-\mathrm{Tm}$ and $\mathrm{Yb}$-Er rare earth dopants were sintered at various temperatures $\left(500-800^{\circ} \mathrm{C}\right)$ in air or nitrogen flow during 2 or 3 hours at heating rates of $10^{\circ} \mathrm{C} \mathrm{min}^{-1}$. A "fast" heating of the $\mathrm{NaYF}_{4}: \mathrm{Yb}$, Er upconversion phosphors was achieved by placing the powders directly in an $800^{\circ} \mathrm{C}$ preheated furnace.

The relative upconversion luminescence was measured according to the following procedure: Powders of the UC phosphors were filled in glass tubes of 1 
$\mathrm{mm}$ iminer inol satnple holder. The powder densities were the sante for all samples, as the powders were pressed into the glass tubes with glass tips. The samples were excited by a $980-\mathrm{nm}$ IR laser diode coupled to a 1-mm-diameter fiber. The non-focused laser beam illuminated the sample in a spot of about $1 \mathrm{~mm}^{2}$ at a distance of 2-3 $\mathrm{mm}$ from the surface. The UC emission was collected by a Y-fiber, i.e. parallel to the excitation light, and measured by an Ocean Optics SD1000 spectrometer. The reflected IR laser light was blocked by a filter in front of the spectrometer. The laser power was measured by a power meter. The luminescence spectra were corrected for the spectral response of the detection system. The integrated emission peaks yielded the relative UC efficiencies of the powder samples with a reproducibility of $5 \%$.

The size and shape of the as-prepared upconversion nanoparticles were characterized by transmission electron microscopy (TEM) with a Philips CM30 ST $\left(\mathrm{LaB}_{6}\right.$ cathode, operated at $300 \mathrm{kV}$, point resolution $4 \AA$ A). Morphologies were also analyzed by scanning electron microscopy (SEM) with a Zeiss LEO 1530 Gemini. The phase composition was characterized by X-ray diffraction (XRD) patterns recorded with a PANalytical XPert PRO-MPD ( $\mathrm{CuK} \alpha$ radiation, X'Celerator linear detector system, step size of $0.033^{\circ}$, ambient conditions). The mean crystallite size was estimated from X-ray diffraction patterns by the Scherrer equation.

\section{Results and Discussion}

\section{Flame-spray powder morphologies and phase analysis}

$\mathrm{NaYF}_{4}: \mathrm{Yb}, \mathrm{Tm}$ powders were prepared by flamespray synthesis. The obtained nanoparticles had diameters of $20-40 \mathrm{~nm}$. The fuel/oxygen flow rates of $3 / 7,7 / 3$, and $7 / 9 \mathrm{~L} / \mathrm{min}$ resulted in the formation of cubic $\alpha-\mathrm{NaYF}_{4}$ particles, see Fig. 2a. Equation (2) shows the reaction scheme,

$$
\text { Liquid } \rightarrow \mathrm{NaF}+\mathrm{NaYF}_{4}
$$

where liquid corresponds to the melt in the flame before cooling down at the Teflon filter.

The medium $5 / 51 \mathrm{~min}^{-1}$ feeding rate led to a mixed product with hexagonal $(\beta)$ and $\operatorname{cubic}(\alpha)$ phases of sodium yttrium fluoride, see Fig. 2a.

The TEM analysis of this powder revealed the presence of hexagonal particles. The particles have sizes of about $10 \mathrm{~nm}$ with agglomerates up to $50 \mathrm{~nm}$, see Fig. 2b.
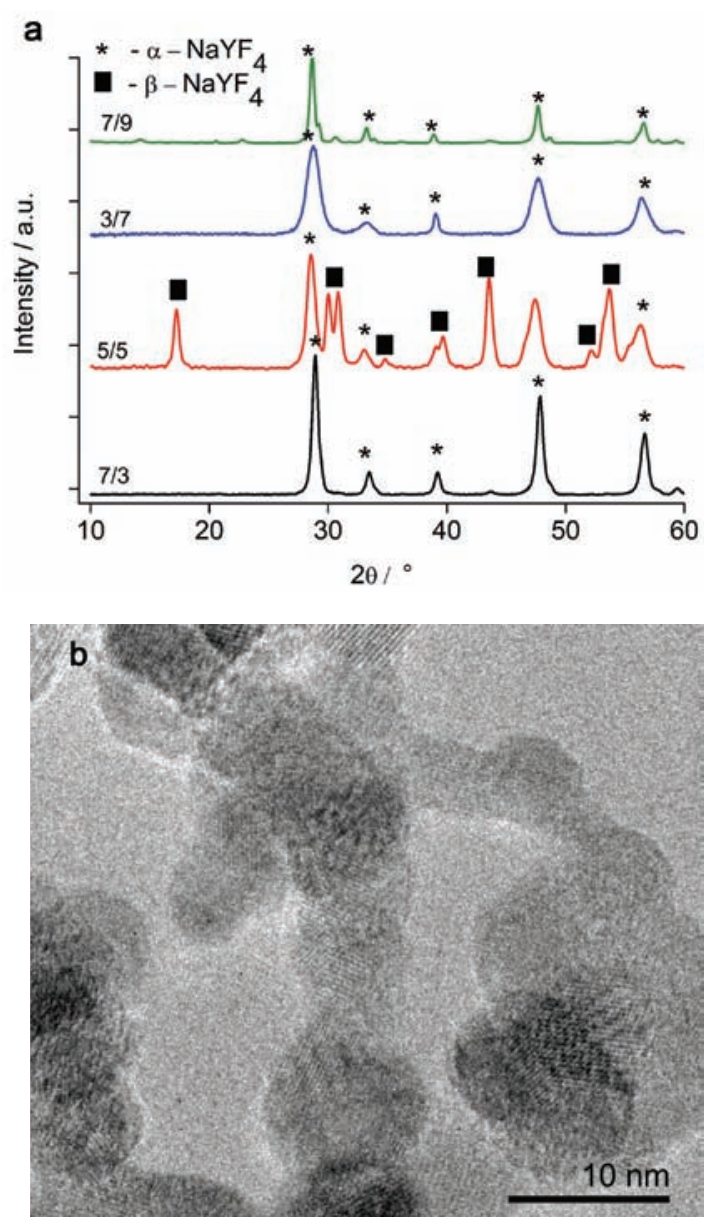

Fig. 2 (a) X-ray diffraction patterns of $\mathrm{NaYF}_{4}$ :Yb,Tm nanoparticles from different fuel/oxygen flow rates and (b) Transmission electron microscopy image of hexagonal $\mathrm{NaYF}_{4}: \mathrm{Yb}, \mathrm{Tm}$ nanoparticles obtained from fuel/oxygen flow rates of $5 / 5 \mathrm{~L} /$ $\min$.

By the BET method, specific particle surface areas from 29.5 to $31 \mathrm{~m}^{2} \mathrm{~g}^{-1}$ were determined for nanoparticles prepared in oxidic or reduced atmospheres.

The calculated particle diameters according to equation (3) were 47 and $45 \mathrm{~nm}$, respectively,

$$
d_{B E T}=\frac{6}{\rho \cdot S S A}
$$

where $\rho=4.3 \mathrm{~g} \mathrm{~cm}^{-3}$ is the density of $\beta-\mathrm{NaYF}_{4}$ (Sobolev, 2000) and SSA is the specific surface area (Sobolev et al., 1963).

The SEM micrographs of flame-sprayed $\mathrm{NaYF}_{4}: \mathrm{Yb}$, $\mathrm{Tm}$ also demonstrated the homogeneous distribution of nanoparticles without any visible micron-sized agglomerates, see Fig. 3a. These particles are stable at room temperature under atmospheric conditions. Images of the as-prepared $\mathrm{NaYF}_{4}: \mathrm{Yb}$,Er nanoparticles show agglomerated clusters in the 100 -nm range with 


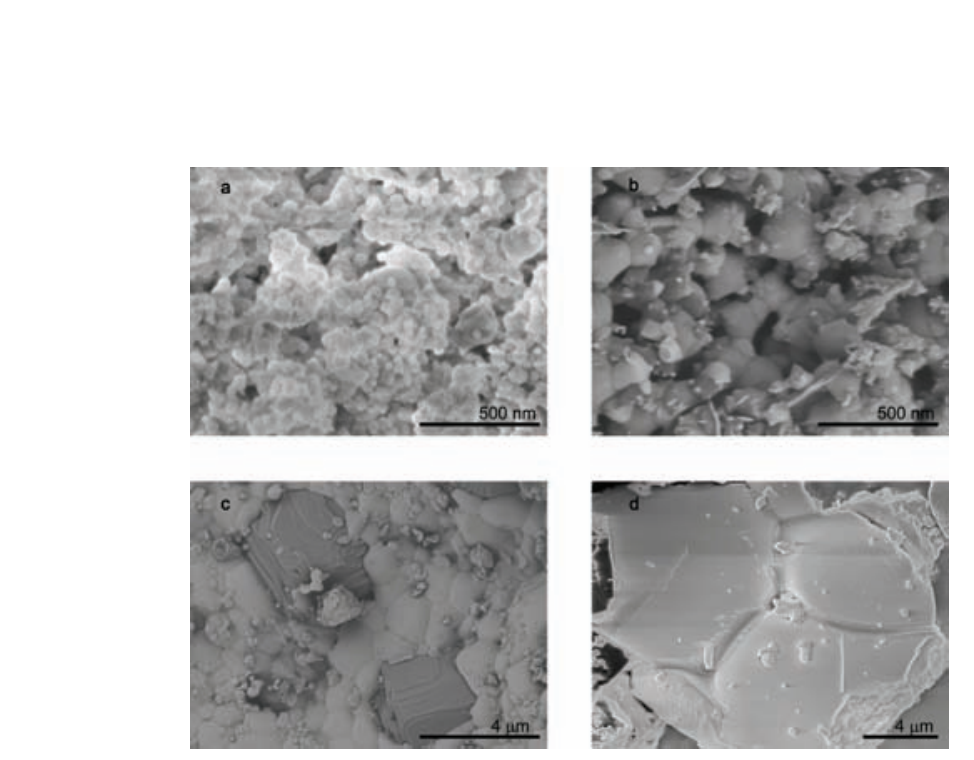

Fig. 3 SEM micrographs of sodium yttrium fluorides prepared by the flame-spray method. (a) and (b) show highly anisotropic hexagonal nanoparticles of $\mathrm{NaYF}_{4}: \mathrm{Yb}, \mathrm{Tm}$ and $\mathrm{Yb}, \mathrm{Er}$, respectively. (c) and (d) show images of micron-sized crystallites of $\mathrm{NaYF}_{4}$ and cubic $\mathrm{Y}_{2} \mathrm{O}_{3}$, respectively, after sintering at $700^{\circ} \mathrm{C}$ in ambient atmosphere.

hexagonal crystallites of less than $50 \mathrm{~nm}$ in size, see Fig. 3b. It correlates to previously measured BET and TEM particle size estimations. During sintering, the grains grow and micron-sized cubic crystals of $\mathrm{Y}_{2} \mathrm{O}_{3}$ form, see Fig. 3c. The image of a fragment in Fig. 3d shows narrow grain boundaries of $\beta-\mathrm{NaYF}_{4}$ crystals after 3 hours sintering at $700^{\circ} \mathrm{C}$ under constant nitrogen flow.

\section{Thermal treatment of UC phosphors}

The thermal behavior of the synthesized powders was studied by differential thermal analysis (DTA), see Fig. 4a. At low temperatures, the adsorbed water was released from the sample according to a weight loss of $0.3 \mathrm{wt} \%$ In addition, the DTA signal indicates a minor exothermal peak at $380^{\circ} \mathrm{C}$ It may correspond to the formation of traces of cubic yttrium oxide. At $400-500^{\circ} \mathrm{C}$, the TG curve shows a step correlated to an endothermic peak on the DTA curve.

Analysis of the phase composition of upconversion phosphors sintered at $500^{\circ} \mathrm{C}$ showed decreasing halfwidths of the Bragg peaks which correspond to an increased size of the crystallites. The $\mathrm{NaYF}_{4}$ : $\mathrm{Yb}, \mathrm{Tm}$ powders were sintered at temperatures from $500^{\circ} \mathrm{C}$ to $800^{\circ} \mathrm{C}$. The XRD curves up to $700^{\circ} \mathrm{C}$ give no hint for a phase transition, see Fig. $\mathbf{4 b}$. The sintering at $800^{\circ} \mathrm{C}$ shows a partial transition of sodium yttrium fluoride from its cubic to the hexagonal phase. According to the NaF-YF 3 (Thoma et al., 1966) phase diagram, see Fig. $\mathbf{1 b}$, the hexagonal $\beta-\mathrm{NaYF}_{4}$ phase is stable at room temperature whereas the high-temperature
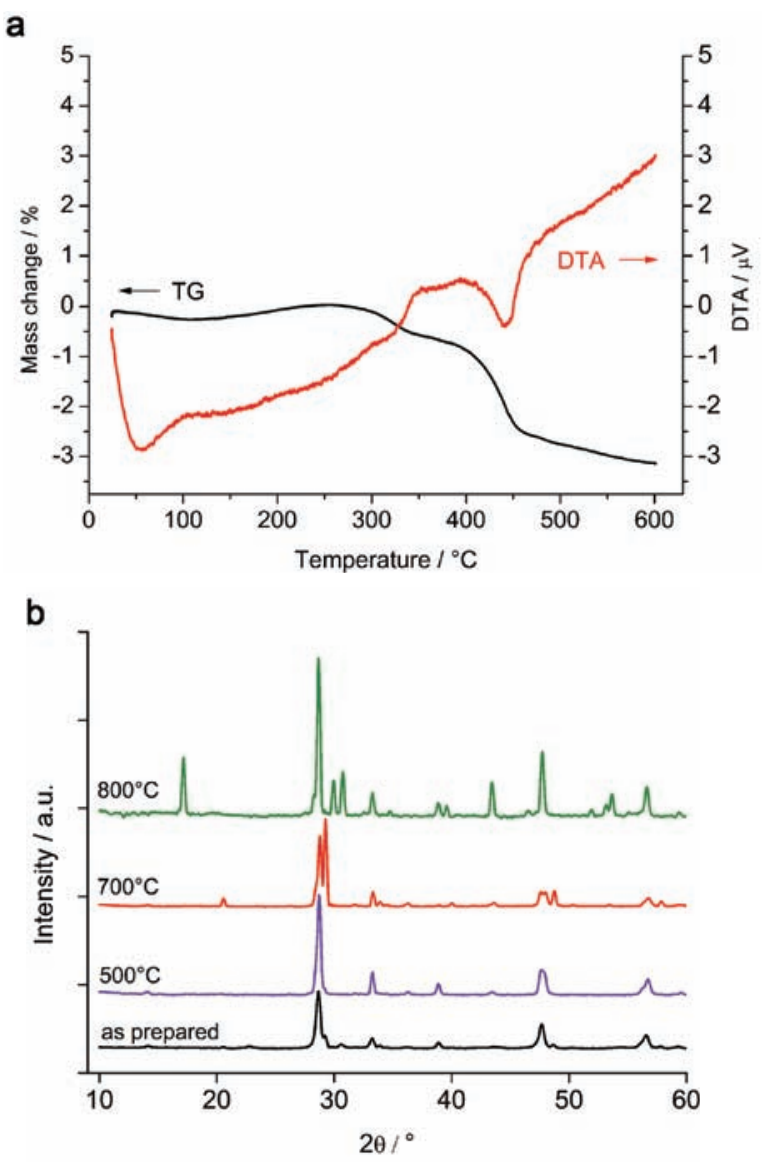

Fig. 4 (a) Differential thermal analysis (DTA) and thermal gravimetric (TG) signals of $\mathrm{NaYF}_{4}: \mathrm{Yb}$, Tm nanoparticles and (b) XRD diffraction patterns for different sintering temperatures of $\mathrm{NaYF}_{4}: \mathrm{Yb}, \mathrm{Er} .500^{\circ} \mathrm{C}$ and $700^{\circ} \mathrm{C}$ sintering was applied at a $10^{\circ} \mathrm{C} \mathrm{min}^{-1}$ heating rate. For $800^{\circ} \mathrm{C}$, a "fast" heating is achieved by placing the powder directly into the preheated furnace.

cubic $\alpha$-phase is stable above $691{ }^{\circ} \mathrm{C}$. Thus cubic $\mathrm{NaYF}_{4}$ is obtained in the synthesis as a metastable, kinetically stabilized phase. Only at high enough temperatures, close to the $\alpha$ - $\beta$ phase transition, can the $\alpha$-phase overcome the activation energy barrier and transform into the $\beta$-phase. The ' $800^{\circ} \mathrm{C}$ ' curve in Fig. $\mathbf{4 b}$ shows a partial $\alpha-\beta$ phase transition. The sample temperature had obviously not been $800^{\circ} \mathrm{C}$ in this experiment, because then no $\beta$-phase would be obtained at all, but it had been high enough to partially activate the transition.

The thermal treatment at $700^{\circ} \mathrm{C}$ in an air flow during two hours led to the formation of $\mathrm{Y}_{2} \mathrm{O}_{3}$. This hydrolysis results in $\mathrm{HF}$ gas evolution and leaves $\mathrm{Y}_{2} \mathrm{O}_{3}$ and $\mathrm{NaF}$ behind, cf. equation (4).

$$
2 \mathrm{NaYF}_{4}+3 \mathrm{H}_{2} \mathrm{O} \rightarrow 2 \mathrm{NaF}+\mathrm{Y}_{2} \mathrm{O}_{3}+6 \mathrm{HF}
$$



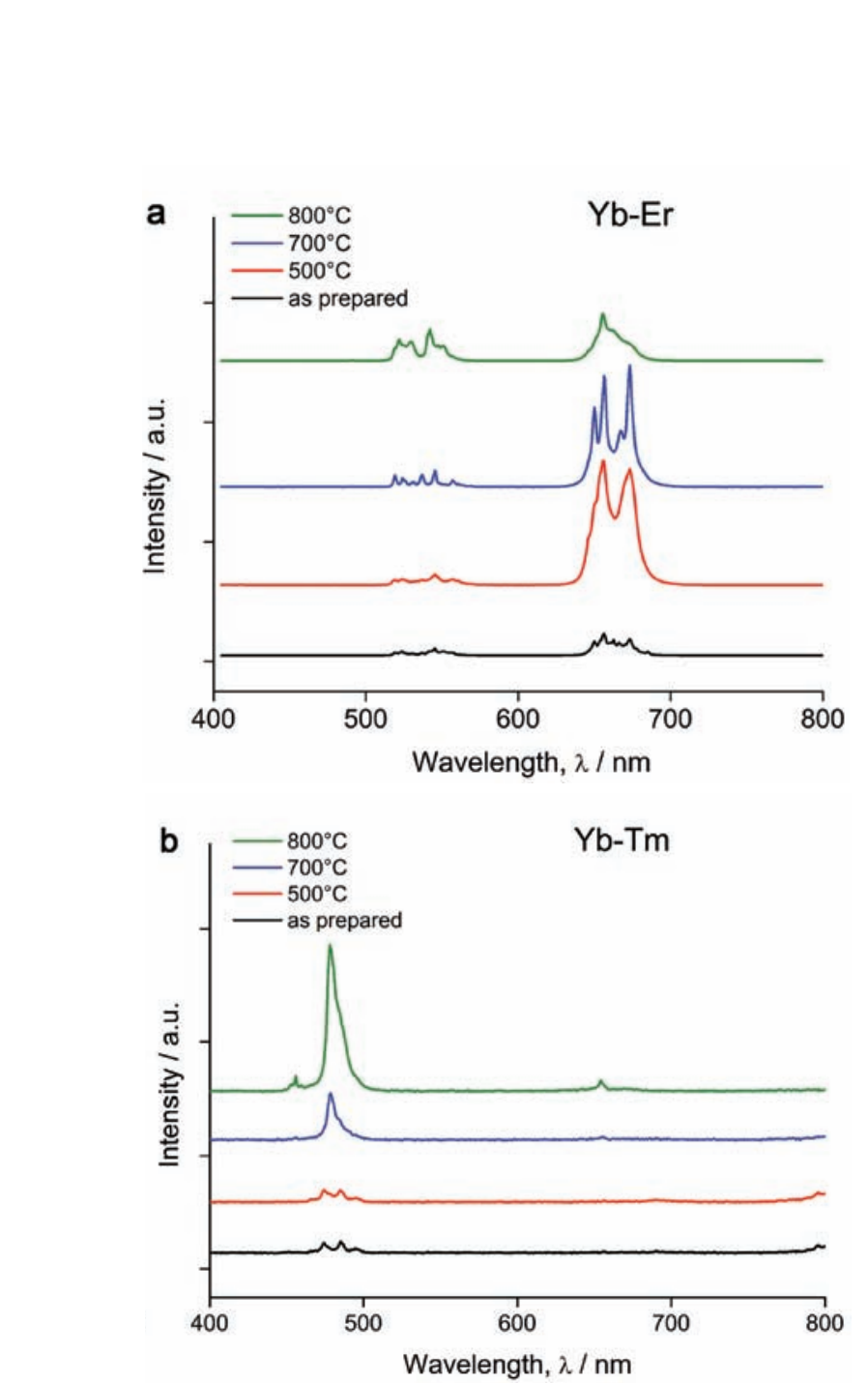

Fig. 5 Upconversion luminescence emission of $\mathrm{NaYF}_{4}$ with $\mathrm{Yb}-\mathrm{Er}(\mathrm{a})$ and $\mathrm{Yb}-\mathrm{Tm}$ (b) rare earth dopant couples. The relative peak intensities increase after sintering from $500^{\circ} \mathrm{C}$ to $800^{\circ} \mathrm{C}$.

In order to transform the cubic phase towards the more favorable hexagonal phase, the powders were sintered in vacuum. The X-ray diffraction patterns of samples treated at $500^{\circ} \mathrm{C}$ demonstrate the growth of crystals, see Fig. $\mathbf{4 b}$, but no formation of hexagonal $\mathrm{NaYF}_{4}$. Crystallite sizes derived from the Scherrer Equation show a growth from $40 \mathrm{~nm}$ to $80 \mathrm{~nm}$. Sobolev et al. (Sobolev et al., 1963) earlier demonstrated that the $\mathrm{NaYF}_{4}$ hexagonal phase undergoes a phase transition into $\mathrm{NaYF}_{4}$ with cubic symmetry at $600^{\circ} \mathrm{C}$.

Further examinations of the flame-spray synthesis conditions and thermal treatment modes such as cooling rate are required. Flame pyrolysis allows the synthesis of nanocrystalline upconversion phosphors with a high surface area which show luminescence (Fig. 5b, 6a and b).

\section{Thermal behavior and luminescence of $\mathrm{NaYF}_{4}$ :Yb, Er}

$\mathrm{NaYF}_{4}: \mathrm{Yb}$, Er samples were prepared using a 7/9 (L / min) feeding rate. The particles revealed green and red luminescence on excitation with a $980-\mathrm{nm}$ IR laser. After sintering at $500^{\circ} \mathrm{C}$ and $700^{\circ} \mathrm{C}$, the luminescence intensity increased because the crystallites grew in size. Fast heating, i.e. placing powders into a preheated furnace at $800^{\circ} \mathrm{C}$, resulted in rapid formation of hexagonal sodium yttrium fluoride, see Fig. $\mathbf{4 b}$. As a result, the green emission intensity increased, see Fig.5a. Phosphors sintered under an inert atmosphere formed oxide phases, which in turn intensified the red emission in the UC luminescence spectrum, see Fig. 5a. Yttrium oxide formation in the inert atmosphere is based on phase kinetics and prior built-in oxygen. This embedding happens during flame pyrolysis in an oxygen-containing environment. The formation of micron-size crystallites is observed on the SEM micrographs, see Fig. 3c. A slow heating rate of $10^{\circ} \mathrm{C} \mathrm{min}^{-1}$ yielded a mixture of yttrium oxide and cubic $\mathrm{NaYF}_{4}$; the fast heating leads to hexagonal $\mathrm{NaYF}_{4}$ formation.

The luminescence spectra of upconversion phosphors doped with $\mathrm{Yb}^{3+}$ and $\mathrm{Tm}^{3+}$ show two characteristic visible emissions upon 980-nm excitation, see Fig. 5b. The red emission originates from the ${ }^{1} \mathrm{G}_{4} \rightarrow$ ${ }^{3} \mathrm{~F}_{4}$ transition. The blue emission consists of the two neighboring transitions of ${ }^{1} \mathrm{G}_{4} \rightarrow{ }^{3} \mathrm{H}_{6}$ and ${ }^{1} \mathrm{D}_{2} \rightarrow{ }^{3} \mathrm{~F}_{4}$. Upconversion luminescence spectra also show emissions in the ultraviolet range $\left({ }^{1} \mathrm{D}_{2} \rightarrow{ }^{3} \mathrm{H}_{6}\right.$ and ${ }^{1} \mathrm{I}_{6} \rightarrow$ ${ }^{3} \mathrm{~F}_{4}$ ). Higher sintering temperatures increase the luminescence intensity because larger crystallites have a smaller surface-to-volume ratio and therefore less defects (Suyver et al., 2006). The $\mathrm{Yb}^{3+}, \mathrm{Er}^{3+}$-doped $\alpha$ $-\mathrm{NaYF}_{4}$ shows a significantly higher red $\left({ }^{4} \mathrm{~F}_{9 / 2} \rightarrow{ }^{4} \mathrm{I}_{15 / 2}\right)$ than green $\left({ }^{4} \mathrm{~S}_{3 / 2} \rightarrow{ }^{4} \mathrm{I}_{15 / 2}\right)$ emission, see Fig. 5a. However, for the "fast heating" at $800^{\circ} \mathrm{C}$ sample, the green-to-red emission ratio becomes higher because hexagonal $\beta-\mathrm{NaYF}_{4}$ formed which has a significantly stronger green emission. Photographs of the UC emission of the respective samples are shown in Fig. 6.

\section{Conclusions}

Pre-designed complex nanostructures with characteristic properties are built up by assembling their functional units step by step. In this regard, gasphase methods have a great potential for industrially realizing some of the promises of nanotechnology. Their scaling potential and access to various types of precursors covers a plethora of nanostructures such as metals, oxides, salts, and complex compounds. 

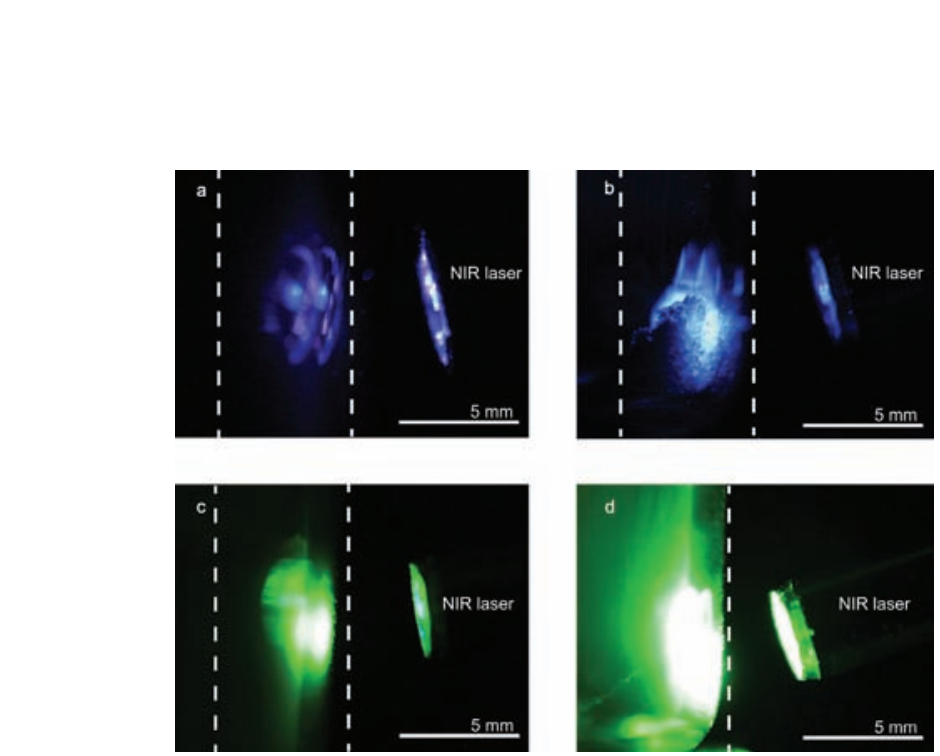

Fig. 6 Photographs of the UC luminescence of $\mathrm{Yb}^{3+}$, $\mathrm{Tm}^{3+}(\mathrm{a}, \mathrm{b})$ and $\mathrm{Yb}^{3+}, \mathrm{Er}^{3+}(\mathrm{c}, \mathrm{d})$-doped nanophosphors. The thermal treatment of powders at $800^{\circ} \mathrm{C}$ significantly increased the intensity of the visible emissions for the $\mathrm{Yb}^{3+}, \mathrm{Tm}^{3+}$ (b) and the $\mathrm{Yb}^{3+}, \mathrm{Er}^{3+}$ (d) phosphors.

In the present work, a successful bottom-up access through a refined flame-spray technique provides access to complex non-oxide particles such as rareearth-doped sodium yttrium fluorides. The co-doping with $\mathrm{Yb}-\mathrm{Tm}$ and $\mathrm{Yb}-\mathrm{Er}$ ion couples leads to blue and green upconversion luminescence, respectively. Particles of less than $50 \mathrm{~nm}$ in size were obtained under reducing conditions as cubic $\mathrm{NaYF}_{4}$. It was possible to tune a cubic to hexagonal phase transition by thermal treatment of the nanomaterial. A strongly enhanced UC luminescence intensity was observed for the $\beta-\mathrm{NaYF}_{4}$. Upconversion luminescence spectra showed a correlation between crystallite size (i.e. low surface area) and luminescence intensity. Oxide impurities reduced the green and increased the red $\mathrm{UC}$ emissions in $\mathrm{Yb}^{3+}, \mathrm{Er}^{3+}$-doped phosphors.

\section{References}

1) Adityawarman, D., Voigt, A., Veit, P. and Sundmacher, K. (2005): Precipitation of $\mathrm{BaSO}_{4}$ nanoparticles in a non-ionic microemulsion: Identification of suitable control parameters, Chem Eng Sci, Vol.60, pp.33733381.

2) Athanassiou, E. K., Grass, R. N. and Stark, W. J. (2010): One-step large scale gas phase synthesis of $\mathrm{Mn}^{2+}$ doped $\mathrm{ZnS}$ nanoparticles in reducing flames, Nanotechnology, Vol.21, 215603, doi:10.1088/09574484/21/21/215603

3) Auzel, F. (2004): Upconversion and anti-stokes processes with $\mathrm{f}$ and d ions in solids, Chem Rev, Vol.104, pp.139-173.

4) Blasse, G. and Grabmaier, B. C. (1994). "Luminescent
Materials”, Springer-Verlag, Berlin.

5) Brunner, T. J., Grass, R. N. and Stark, W. J. (2006): Glass and bioglass nanopowders by flame synthesis, Chem Comm, pp.1384-1386.

6) Cassell, A. M., Raymakers, J. A., Kong, J. and Dai, H. J. (1999): Large scale CVD synthesis of single-walled carbon nanotubes, J. Phys Chem B, Vol.103, pp.64846492.

7) Chen, L. Y., Shen, Y. M. and Bai, J. F. (2009): Largescale synthesis of uniform spinel ferrite nanoparticles from hydrothermal decomposition of trinuclear heterometallic oxo-centered acetate clusters, Materials Letters, Vol.63, pp.1099-1101.

8) Grass, R. N. and Stark, W. J. (2005): Flame synthesis of calcium-, strontium-, barium fluoride nanoparticles and sodium chloride, Chem Comm, pp.1767-1769.

9) Grass, R. N. and Stark, W. J. (2006): Gas phase synthesis of fcc-cobalt nanoparticles, J. Mater Chem, Vol.16, pp.1825-1830.

10) Grass, R. N., Athanassiou, E. K. and Stark, W. J. (2007): Magnetische Trennung von organischen Verbindungen durch kovalent funktionalisierte Cobaltnanopartikel, Angewandte Chemie, Vol.119, pp.49964999.

11) Heer, S., Kömpe, K., Güdel, H. U. and Haase, M. (2004): Highly Efficient Multicolour Upconversion Emission in Transparent Colloids of LanthanideDoped $\mathrm{NaYF}_{4}$ Nanocrystals, Advanced Materials, Vol.16, pp.2102-2105.

12) Hosokawa, M. (2008), In: "Nanoparticle Technology Handbook”, Hosokawa, M., Nogi, K., Naito, M. and Yokoyama,T., , editors, Amsterdam: Elsevier, pp.v-vi.

13) Huber, M., Stark, W. J., Loher, S., Maciejewski, M., Krumeich, F. and Baiker, A. (2005): Flame synthesis of calcium carbonate nanoparticles, Chem Comm, pp.648-650.

14) Jung, C. H., Lee, H. G., Kim, C. J. and Bhaduri, S. B. (2003): Synthesis of Cu-Ni Alloy Powder Directly from Metal Salts Solution, J. Nanopart Res, Vol.5, pp.383-388.

15) Jung, C. H., Jalota, S. and Bhaduri, S. B. (2005): Quantitative effects of fuel on the synthesis of $\mathrm{Ni} / \mathrm{NiO}$ particles using a microwave-induced solution combustion synthesis in air atmosphere, Materials Letters, Vol.59, pp.2426-2432.

16) Kang, Y. C., Sohn, J. R., Yoon, H. S., Jung, K. Y. and Park, H. D. (2003): Improved Photoluminescence of $\mathrm{Sr}_{5}\left(\mathrm{PO}_{4}\right)_{3} \mathrm{Cl}: \mathrm{Eu}^{2+}$ Phosphor Particles Prepared by Flame Spray Pyrolysis, J. Electrochem Soc, Vol.150, pp.H38-H42.

17) Lee, S. B., Jang, I. C., Lim, H. H., Aravindan, V., Kim, H. S. and Lee, Y. S. (2010): Preparation and electrochemical characterization of $\mathrm{LiFePO}_{4}$ nanoparticles with high rate capability by a sol-gel method, J. Alloy Compd, Vol.491, pp.668-672.

18) Lim, S. F., Riehn, R., Tung, C. K., Ryu, W. S., Zhuo, R., Dalland, J. and Austin, R. H. (2009): Upconverting nanophosphors for bioimaging, Nanotechnology, 
29) Stark, W.J., Mädler, L., and Pratsinis, S.E. (2004). Metal oxides prepared by flame spray pyrolysis. Patent WO2004005184.

$198 e^{r}$ Mratin, N., Boutinaud, P., Mahiou, R., Cousseins, J. C.

O Wand Bouderbala, M. (1999): Preparation of fluorides at 80 degrees $\mathrm{C}$ in the NaF-(Y,Yb,Pr)F-3 system, J. Mater Chem, Vol.9, pp.125-128.

20) Muller, K., Klapper, M. and Mullen, K. (2006): Synthesis of conjugated polymer nanoparticles in nonaqueous emulsions, Macromol Rapid Comm, Vol.27, pp.586-593.

21) Musyanovych, A., Schmitz-Wienke, J., Mailander, V., Walther, P. and Landfester, K. (2008): Preparation of biodegradable polymer nanoparticles by miniemulsion technique and their cell interactions, Macromol Biosci, Vol.8, pp.127-139.

22) Richard, B. S. and Shalav, A. (2005): The role of polymers in the luminescence conversion of sunlight for enhanced solar cell performance, Synth Metals, Vol.154, pp.61-64.

23) Rossier, M., Schaetz, A., Athanassiou, E. K., Grass, R. N. and Stark, W. J. (2011): Reversible As(V) adsorption on magnetic nanoparticles and $\mathrm{pH}$ dependent desorption concentrates dilute solutions and realizes true moving bed reactor systems, Chem Eng J., Vol.175, pp.244-250.

24) Sandrock, T., Scheife, H., Heumann, E. and Huber, G. (1997): High-power continuous-wave upconversion fiber laser at room temperature, Opt Lett, Vol.22, pp.808-810.

25) Sobolev, B. P., Mineev, D. A. and Pashutin, V. P. (1963): Low-temperature hexagonal modification of $\mathrm{NaYF}_{4}$ having gagarinite structure, Doklady Akademii Nauk Sssr, Vol.150, pp.791-794.

26) Sobolev, B. P. (2000). Introduction to Materials Science of Multicomponent Metal Fluoride Crystals. In: "Rare Earth Trifluorides”, Barcelona: Inst. D Estudis Catalan', pp.202-208.

27) Sommerdijk, J. L. (1973): Influence of the host lattice on the infrared-excited blue luminescence of $\mathrm{Yb}^{3+}$, $\mathrm{Tm}^{3+}$-doped compounds, J. Lum, Vol.8, pp.126-130.

28) Stark, W. J., Pratsinis, S. E., Maciejewski, M., Loher, S. F. and Baiker, A. (2005). Flame synthesis of metal salt nanoparticles, in particular calcium and phosphate comprising nanoparticles, Patent WO2005087660. 


\section{Author's short biography}

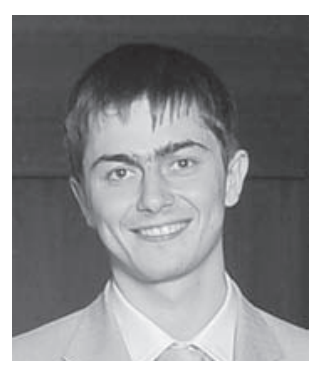

\section{Alex Stepuk}

Alex Stepuk received a BSc. in materials science at Moscow State University. He graduated with an MSc of the Materials Science Department at ETH Zurich with a pioneering thesis on the implementation of upconversion phosphors in dental photopolymers. He is currently a PhD candidatein the group of Prof. Wendelin J. Stark at the Department of Chemistry and Applied Biosciences at ETH Zurich. His research interests are interdisciplinary, covering applications of flame-spray-derived nanoparticles in dental materials and orthopedics, materials for energy conversion and polymers in medicine.

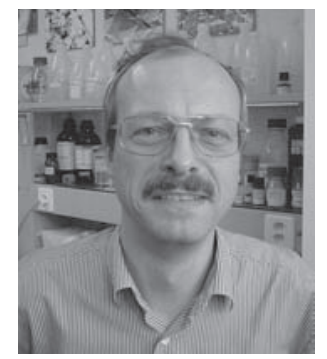

\section{Karl W. Krämer}

Karl W. Krämer received his chemistry diploma (1988) and his Dr. rer. nat. (1991) from the Justus-Liebig University, Giessen, Germany. He is the group leader of solid state analytics at the Department of Chemistry of the University of Bern, Switzerland. His research focuses on the synthesis of anhydrous metal halides, their crystal growth, and investigation of spectroscopic and magnetic properties. Recent topics are upconversion phosphors, e.g. $\quad \beta$-NaYF4:Yb,Er or Yb,Tm, Ce3+-doped scintillators, e.g. LaBr3:Ce, and quantum spin ladders, e.g. [piperidinium] $2 \mathrm{CuBr} 4$.

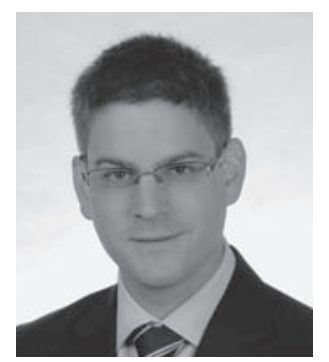

\section{Wendelin J. Stark}

Wendelin J. Stark received his master'sdegree in chemistry in 2000, followed by a $\mathrm{PhD}$ in mechanical engineering in 2002, both from ETH Zurich. In 2004, he founded the Functional Materials Laboratory within the Departments of Chemistry and Applied Bioscience at the ETH Zurich. His research group pursues application-oriented research at the interface of chemistry with materials science and medicine. 